\title{
Identification of a new C-terminal splice variant of Cav1.3 L-type calcium channels with unique functional properties
}

\author{
Gabriella Juhasz-Vedres, Anja Scharinger, Mathias Gebhart, Perrine Busquet, Chiara Poggiani, Simone B Sartori, \\ Martina J Sinnegger-Brauns, Alexandra Koschak, Jörg Striessnig*
}

From 17th Scientific Symposium of the Austrian Pharmacological Society (APHAR). Joint meeting with the Hungarian Society of Experimental and Clinical Pharmacology (MFT)

Innsbruck, Austria. 29-30 September 2011

\section{Background}

In L-type voltage-gated calcium channels (VGCCs) the long C-terminal tail contains several sites for modulation by protein-protein interaction. $\mathrm{Ca}_{\mathrm{V}} 1.3$ VGCCs $\left(\mathrm{Ca}_{\mathrm{V}} 1.3_{\mathrm{L}}\right)$ activate at negative voltages and support sinoatrial node pacemaking and hearing, and shape neuronal excitability. In $\mathrm{Ca}_{\mathrm{V}} 1.3_{\mathrm{L}}$ an intermolecular automodulatory $\mathrm{C}$-terminal interaction (CTM) has been described which affects channel gating. CTM is characterized by interaction of a distal C-terminal regulatory domain (DCRD) with a more proximal regulatory domain (PCRD). If this CTM is absent as in previously described short $\mathrm{Ca}_{\mathrm{V}} 1.3_{42 \mathrm{~A}}$, calcium-dependent inactivation (CDI) increases and the channel activation range shifts to more negative voltages (i.e. "short" gating properties). Here we show that alternative splicing in exon 43 creates a new short splice variant $\mathrm{Ca}_{\mathrm{V}} 1.3_{43 \mathrm{~S}}$ found in human and mouse brain. It lacks CTM, but still contains the PCRD motif, in contrast to previously described $\mathrm{Ca}_{\mathrm{V}} 1.3_{42 \mathrm{~A}}$. Semiquantitative PCR experiments showed that in mouse brain $39 \%$ of $\mathrm{Ca}_{\mathrm{V}} 1.3$ channels contain exon $43 \mathrm{~S}$ contrary to heart (6\% 43S).

\section{Methods and results}

Biophysical analysis showed "short" gating properties for $\mathrm{Ca}_{V} 1.3_{43 \mathrm{~S}}$ in both $15 \mathrm{mM}$ and $2 \mathrm{mM}$ external $\mathrm{Ca}^{2+}$ when co-expressed with $\beta 3$ and $\alpha 2 \delta$-1 subunits in tsA-201 cells. In $2 \mathrm{mM} \mathrm{Ca}^{2+}$ the inactivation rate of $\mathrm{Ca}_{V} 1.3_{43 \mathrm{~S}}$ was faster for $\mathrm{Ca}_{\mathrm{V}} 1.3_{\mathrm{L}}$, but slower for $\mathrm{Ca}_{\mathrm{V}} 1.3_{42 \mathrm{~A}}$ (\% inactivation after
$100 \mathrm{~ms}$ at $\mathrm{V}_{\text {max }}: \mathrm{Ca}_{\mathrm{V}} 1.3_{42 \mathrm{~A}}: 64.5 \pm 3.5 \% ; \mathrm{Ca}_{\mathrm{V}} 1.3_{43 \mathrm{~S}}: 52 \pm$ $\left.4.5 \%, \mathrm{Ca}_{\mathrm{V}} 1.3_{\mathrm{L}}: 37.4 \pm 3 \%, \mathrm{p}<0.001\right)$ by affecting the extent of CDI. Due to a presence of PCRD, DCRD-containing C-terminal fragments from $\mathrm{Ca}_{V} 1.3$ or $\mathrm{Ca}_{V} 1.2$ channels could restore $\mathrm{Ca}_{\mathrm{V}} 1.3_{\mathrm{L}}$ gating behaviour. Indeed, co-expression of GFP-Ca $1.2_{\mathrm{C} 349}$ fully restored long channel gating properties in $\mathrm{Ca}_{\mathrm{V}} 1.3_{43 \mathrm{~S}}\left(\mathrm{~V}_{0.5}: \mathrm{Ca}_{\mathrm{V}} 1.3_{43 \mathrm{~S}}+\mathrm{GFP}-\mathrm{Ca}_{\mathrm{V}} 1.2_{\mathrm{C} 349}\right.$ : $\left.1.37 \pm 1.3 \mathrm{mV} ; \mathrm{Ca}_{\mathrm{V}} 1.3_{\mathrm{L}}:-2.4 \pm 0.6 \mathrm{mV}\right)$. C-terminal splicing also changed $\mathrm{I}_{\mathrm{Ca}}$ kinetics during stimuli mimicking trains of action potential waveforms, revealing a lower total $\mathrm{I}_{\mathrm{Ca}}$ during AP bursts in short splice variants.

\section{Conclusions}

Taken together, our data indicate that $\mathrm{Ca}_{\mathrm{V}} 1.3 \mathrm{C}$-terminal splicing can serve as an important mechanism to finetune the dynamics of calcium entry in neurons in an activity dependent manner.

\section{Acknowledgements}

Supported by FWF P-20670 JS, P-22528 AK, and SFB F44.

Published: 5 September 2011

doi:10.1186/1471-2210-11-S2-A44

Cite this article as: Juhasz-Vedres et al: Identification of a new C-

terminal splice variant of $\mathrm{Ca}_{\mathrm{v}} 1.3$ L-type calcium channels with unique functional properties. BMC Pharmacology 2011 11(Suppl 2):A44.

* Correspondence: joerg.striessnig@uibk.ac.at

Department of Pharmacology and Toxicology, Institute of Pharmacy, and Center for Molecular Biosciences Innsbruck (CMBI), University of Innsbruck, 6020 Innsbruck, Austria 